\title{
El Programa Pueblos Mágicos: el patrimonio cultural como generador de nuevas dinámicas en la red de política pública de Chiapa de Corzo
}

Recibido: 23/07/2015 - Aceptado: 19/08/2016

Beatriz de la Rosa Flores*

Graciela Cruz Jiménez

Marcelino Castillo Nechar

Centro de Investigación y Estudios Turísticos

Universidad Autónoma del Estado de México

\section{Resumen}

La creación en México del Programa Pueblos Mágicos en 2001 obedeció al interés de su gobierno por consolidar destinos turísticos con atributos culturales e históricos, por lo que en términos normativos persigue tanto la conservación como la protección de su patrimonio cultural, y su manejo en cuanto atractivo turístico. A la vez, la incorporación de una localidad al programa supone la participación de diversos actores. En ese sentido, el enfoque de redes de política pública es pertinente para analizar la red formada a partir de su implementación en Chiapa de Corzo, Chiapas. A fin de atender tal propósito, en este artículo se realiza una aproximación metodológica que posibilite, por una parte, identificar a los actores vinculados con la conservación del patrimonio material e inmaterial de la localidad y, por otra, reflexionar sobre la serie de aspectos que encierra el programa.

Palabras clave: Programa Pueblos Mágicos, patrimonio cultural, red de política pública, turismo, actores.

*Correos electrónicos: beatriz_drf@hotmail.com·gracicj@hotmail.com marcanec62@hotmail.com 


\title{
The Magical Towns Program: cultural heritage as a generator of new dynamics in the public policy network of Chiapa de Corzo
}

\author{
Beatriz de la Rosa Flores* \\ Graciela Cruz Jiménez \\ Marcelino Castillo Nechar \\ Centro de Investigación y Estudios Turísticos \\ Universidad Autónoma del Estado de México
}

\begin{abstract}
The creation in Mexico of the Programa Pueblos Mágicos (Magical Towns Program) in 2001 was a result of its government's interest to consolidate travel destinations with touristic and historic attributes. In normative terms, this decision pursues the conservation and protection of its cultural heritage and its management as a touristic destination. The incorporation of a city or municipality to this program represents the participation of numerous actors. In this sense, the focus on public policy networks is relevant for analyzing the network created by its implementation in Chiapa de Corzo, Chiapas. To attend this purpose, this article presents a methodological approach that allows the identification of actors related to the conservation of the tangible and intangible heritage while enabling a reflection on a series of aspects related to the program.
\end{abstract}

Key words: Programa Pueblos Mágicos (Magical Towns Program), cultural heritage, public policy network, tourism, actors.

*E-mails: beatriz_drf@hotmail.com·gracicj@hotmail.com·marcanec62@hotmail.com 


\section{Introducción}

El posicionamiento del turismo como una actividad prioritaria en el nivel mundial obedeció, en un principio, a su contribución a las economías de diversos países. Sin embargo, la producción científica más reciente atiende a su comprensión más profunda e integral, en contextos donde se reconoce que puede crear condiciones adversas en distintos órdenes, entre ellos los relacionados a procesos de participación en la toma de decisiones y, en consecuencia, en el manejo del patrimonio que integra su oferta.

En México se ha concedido al turismo una relevancia particular y ha generado productos que atienden, en primera instancia, al mercado doméstico, al estadounidense y canadiense, además de mercados emergentes como el inglés, español, francés, alemán, ruso, japonés e italiano. Si bien la oferta turística nacional se ha caracterizado por los destinos de sol y playa que todavía forman parte importante de esta, su política turística se reorientó para atender las necesidades e intereses de nuevos mercados, además de responder a las tendencias mundiales; entre estas figuran los destinos que dirigen su oferta a distintos sectores: servicios de lujo; personas de la tercera edad o con alguna discapacidad o que incorporen acciones relacionadas con la responsabilidad medioambiental y sustentable.

Como parte de la referida reorientación de la política turística adoptada en el periodo presidencial 2001-2006, se ha procurado el aprovechamiento del patrimonio cultural; para ello se constituyeron diversos programas encaminados a la promoción y desarrollo de destinos caracterizados por su oferta cultural. Como resultado de esta acción fue creado el Programa Pueblos Mágicos, vinculado al aprovechamiento de localidades cuyos atributos culturales se visualizaran en cuanto elementos representativos de la identidad nacional distinguida por su herencia prehispánica y española (Florescano, 2005, pp. 33-35; Velázquez, 2013, p. 106).

Es así que ese programa, constituido en el discurso como un elemento para revalorizar el patrimonio cultural, implicó el surgimiento de relaciones entre actores gubernamentales y no gubernamentales ligados al turismo y al patrimonio, con la finalidad de obtener beneficios económicos, sociales, ambientales y culturales mediante el aprovechamiento del patrimonio (García y Guerrero, 2014, p. 74). 
El Programa Pueblos Mágicos: el patrimonio cultural como generador de nuevas dinámicas en la red de política pública de Chiapa de Corzo

En este contexto, Venturini (2003) y Castillo, Peñaloza y Tamayo (2008) han puesto en duda el aprovechamiento turístico con el argumento de favorecer la preservación del patrimonio cultural; otros autores (Lara y López, 2005; Méndez, 2008; Méndez, 2012; Muñiz-Montero, 2012; Vega y Guerrero, 2014) han cuestionado el impacto del turismo sobre determinadas expresiones culturales y las afectaciones a la identidad que da sentido a los habitantes. Varias críticas se refieren a los impactos que genera esta actividad sobre el destino, como resultado de la homogeneización de los espacios y de la imagen urbana, principalmente en los centros históricos, bajo el propósito de ajustarse a una imagen estandarizada, definida por dependencias gubernamentales u organismos internacionales (Duterme, 2008, p. 18). Asimismo, Palafox, Madrigal y Zizumbo (2011) y Talledos (2012) plantean que estas acciones conllevan la creación de espacios diferenciados y, por tanto, la segregación de algunos habitantes originales del lugar.

Desde esta óptica y tomando como referencia la discusión central de diversos autores (Santana, 1998; Almirón, Bertoncello y Troncoso, 2006; Fernández, 2006; Castellanos, 2008; Castillo, Peñaloza y Tamayo, 2008; Hernández, 2009; Duterme, 2008; Guardado, 2008; Machuca, 2008; Marín, 2008; Valenzuela, Saldaña y Vélez, 2013), es posible argumentar que, bajo determinadas condiciones, el uso del patrimonio como oferta turística responde meramente a una orientación económica, de mercantilización y no preservativa.

Lo anterior evidencia que un tema recurrente al aludir al Programa Pueblos Mágicos corresponde a las implicaciones y transformaciones que provoca en los lugares que ostentan tal nombramiento, no solo en cambios físicos, sino también en las representaciones culturales y las relaciones que se gestan entre los actores locales vinculados directa e indirectamente con la actividad turística. Sobre el particular destacan las investigaciones de Hoyos y Hernández (2008) y Hernández (2009), quienes debaten la validez del programa al señalar que su principal objetivo es favorecer a empresarios con intereses turísticos, más allá de contribuir en verdad al bienestar de los habitantes de las localidades y a la conservación de las expresiones culturales. Aunado a lo anterior, se observa que, desde su concepción y creación por parte del gobierno federal en 2001, el programa obedece y propicia la integración de un Comité Pueblo Mágico que dista de ser representativo, ya que limita la intervención en la toma de decisiones 
a ciertos actores, tanto aquellos relacionados con los gobiernos estatales y municipales, como a prestadores de servicios turísticos (empresarios).

Los criterios para elegir a Chiapa de Corzo como estudio de caso fueron su incorporación y otorgamiento del nombramiento previo a la revisión y reajuste del programa, los antecedentes de su inserción en rutas turísticas y como parte de los productos turísticos destacados en el estado, y su posicionamiento como destino turístico (orientado principalmente a la recepción de visitantes al Cañón del Sumidero). Adicionalmente se tuvieron en cuenta las iniciativas en que participaron varios actores locales y estatales para lograr las declaratorias que en conjunto contribuyeron a obtener el nombramiento. Otro criterio importante en términos prácticos de investigación fue contar con un sponsor o informante clave que hizo posible el acceso a la red integrada por diversos actores vinculados al programa.

El propósito del presente trabajo es aportar un marco para el análisis del Programa Pueblos Mágicos, a partir de identificar las relaciones entre los actores locales que intervinieron en alguna fase del proceso de nombramiento de Chiapa de Corzo, así como en el manejo del programa. Por tanto, el enfoque de redes de política pública permite no solo conocer los alcances y limitaciones de este programa en concreto, sino también la incidencia de los actores y las relaciones resultantes en su manejo y funcionamiento como política turística en un contexto local.

El contenido de este artículo se deriva de la investigación "El Programa Pueblos Mágicos: una política turística y su contribución a la gobernanza. Chiapa de Corzo, Chiapas”. El enfoque que lo sustenta es una perspectiva novedosa para este campo del conocimiento al posibilitar el abordaje de la realidad respecto al análisis del turismo mediante un estudio de caso. A la vez, ha sido escasa la investigación de este tipo de redes para México, pues han sido examinadas principalmente en los contextos estadounidense y anglosajón, de ahí la valía de centrar el estudio en las características de la localidad, pero sin perder de vista su vínculo con elementos exógenos.

El documento se integra de cuatro apartados. El primero se orienta a la definición del patrimonio cultural, su consideración en cuanto atractivo turístico, y la incorporación de su manejo en la normativa nacional; el segundo apartado describe el patrimonio cultural como atractivo turístico en Chiapas; el tercero 
El Programa Pueblos Mágicos: el patrimonio cultural como generador de nuevas dinámicas en la red de política pública de Chiapa de Corzo

expone el contexto en el cual se incorporó a Chiapa de Corzo como pueblo mágico, destacando la importancia de su patrimonio cultural y de su influencia en el logro del nombramiento, y el último apartado presenta un acercamiento metodológico para estudiar la red de política pública formada a partir del Programa Pueblos Mágicos en Chiapa de Corzo.

\section{El patrimonio cultural como atractivo turístico}

Consideración del patrimonio para el desarrollo de la actividad turística

El aprovechamiento del patrimonio cultural en cuanto atractivo turístico no es exclusivo de México; al mismo tiempo, el impulso de nuevos destinos como parte de la oferta responde a los cambios en el nivel mundial derivados de las tendencias dictadas por los turistas.

A partir de la Convención sobre la Protección del Patrimonio Mundial, Cultural y Natural de 1972 fue acuñado el término patrimonio cultural, entendido como aquel que "se conforma por monumentos, conjuntos arquitectónicos y lugares construidos por el hombre o de forma conjunta por hombre y naturaleza destacados por su importancia histórica o estética” (Organización de las Naciones Unidas para la Educación, la Ciencia y la Cultura [Unesco], 1973, pp. 136 y 147).

Como resultado de este evento internacional, en México fue promulgada en 1972 la Ley Federal sobre Monumentos y Zonas Arqueológicos, Artísticos e Históricos (Zabaleta, 2006, p. 50). En ella se incluyeron las directrices y lineamientos con aplicabilidad en el ámbito nacional respecto a la investigación, protección, conservación, restauración y recuperación de los monumentos arqueológicos, artísticos e históricos y de las zonas de monumentos (Unesco, 1973).

Actualmente existe un amplio marco institucional constituido por normativas federales, estatales y municipales aplicables al turismo y al aprovechamiento del patrimonio cultural. Entre las federales destacan: Plan Nacional de Desarrollo; Ley General de Turismo; Ley de Bienes Nacionales; Ley Federal sobre Monumentos y Zonas Arqueológicos, Artísticos e Históricos; Programa Sectorial de Turismo; Reglamento de la Ley Federal de Turismo, y el de la Ley 
Federal sobre Monumentos y Zonas Arqueológicos, Artísticos e Históricos. Las de carácter estatal incluyen: Ley para el Desarrollo y Fomento al Turismo en el Estado de Chiapas, Ley Orgánica Municipal del Estado de Chiapas, y Ley de Protección de Monumentos y Sitios del Estado de Chiapas. Finalmente, en el ámbito municipal se observa la aplicabilidad de las siguientes: Plan de Desarrollo Municipal, Programa de Desarrollo Turístico Municipal y Reglamento de Imagen Urbana. Para el caso de estudio, parte de la normativa corresponde al Acuerdo por el que se Establecen los Lineamientos Generales para la Incorporación y Permanencia al Programa Pueblos Mágicos. Aquí se advierte una alineación de la normativa municipal con la federal en lo referente al reconocimiento de las instituciones y dependencias responsables de salvaguardar el patrimonio.

Respecto a la creación de dependencias encargadas de verificar el cumplimiento de los lineamientos para la salvaguarda del patrimonio cultural, en México este proceso inició en 1972 con el Instituto Nacional de Antropología e Historia (INAH) (Zabaleta, 2006), el cual ocupa un lugar central y directivo en este tenor, junto con el Consejo Nacional para la Cultura y las Artes (Conaculta), el Instituto Nacional de Bellas Artes (INBA), la Secretaría de Educación Pública (SEP), la Secretaría de Turismo (Sectur) y el Fondo Nacional de Fomento al Turismo (Fonatur) (Presidencia de la República, 1972).

De acuerdo con el Conaculta, el patrimonio se conforma por "obras de artistas, arquitectos, músicos, escritores e intelectuales, así como por las obras materiales y no materiales que expresan la creatividad de un pueblo; su lengua, ritos, creencias, lugares y monumentos históricos, literatura, archivos y bibliotecas”. De manera complementaria, el reconocimiento de elementos no tangibles como parte del patrimonio cultural implicó identificar otras formas en que este se manifiesta, entre ellas la inmaterial.

El patrimonio cultural inmaterial es entendido como "las expresiones transmitidas de generación en generación que evolucionan en respuesta a su entorno y contribuyen a generar un sentimiento de continuidad e identidad”. Incluye expresiones que forman parte de las tradiciones de una localidad representadas por sus bailes, fiestas o rituales (Romero Cevallos cit. en Molano, 2007, p. 73).

Casas Jurado, Soler Domingo y Pastor (2012, p. 93) argumentan que el aumento del desplazamiento de visitantes se debe a su creciente interés por destinos que les permitan adentrarse en las costumbres y tradiciones de una región 
El Programa Pueblos Mágicos: el patrimonio cultural como generador de nuevas dinámicas en la red de política pública de Chiapa de Corzo

o localidad. Cabe señalar que la promoción y publicidad son determinantes en la elección de este tipo de destinos, al igual que la creación de destinos turísticos culturales que atienden las exigencias de ese sector de visitantes. Partiendo de los supuestos anteriores, Ávila (2007) señala que la apertura de la cultura a todas las personas, y el incremento de su nivel educativo, también han contribuido a consolidar esta oferta turística. A su vez podrían sumarse incluso factores como la sensibilización por la riqueza cultural, según establecen Ballart y Juan-Tresserras (2005), o la creciente oferta del patrimonio a amplios colectivos que presentan diversas condiciones socioeconómicas (Aceves, 2005, p. 214).

De acuerdo con Ballart (2005, pp. 18-21), los efectos negativos del uso del patrimonio y la cultura como recursos turístico pueden abatirse en la medida en que $a$ ) se internalicen en el nivel local los recursos obtenidos por la actividad, b) se genere mayor sensibilización al uso del patrimonio y c) se otorgue participación a la comunidad local en la toma de decisiones respecto al manejo de este. Juan-Tresserras (2003) apunta que el uso del patrimonio en cuanto atractivo turístico, de forma que se garantice su conservación, requiere de estrategias de planificación de desarrollo turístico a corto, mediano y largo plazo mediante la participación colaborativa entre los sectores público y privado, así como cooperación local y regional.

Sin embargo, algunos autores (Machuca, 1994; Machuca, 2008; Velasco, 2009) coinciden en que la orientación meramente económica del turismo sobre el patrimonio puede demeritar sus alcances positivos e incluso crear situaciones en las que el patrimonio y la cultura se vean amenazados por la modificación de su uso original, su trasformación y deterioro. Se cuestiona el uso del patrimonio vinculado a la generación de marcas (García, 2015) que identifiquen los destinos en que el patrimonio cultural o natural funge como atractivo principal y donde, de acuerdo con Rodríguez y Pérez (2015) y Méndez (2015), se presentan procesos y captación de espacios que albergan a los monumentos considerados patrimonio, dando paso a cambios físicos, de simulación, tematización, escenificación, fabricación de atractivos culturales y, por lo tanto, de pérdida de autenticidad en el afán de captar mayor número de visitantes. 


\section{El patrimonio cultural como atractivo turístico en Chiapas}

El estado de Chiapas se compone de 118 municipios distribuidos en 15 regiones: Metropolitana, Valles Zoque, Mezcalapa, De los llanos, De los bosques, Altos, Frailesca, Norte, Sierra, Selva, Soconusco e Istmo-Costa, Maya, Tulija y Meseta Comiteca (Hernández, 2009; Hacienda, 2013). Su población, según el Censo de Población y Vivienda en 2010, era de 4796580 habitantes, de los cuales más de $40 \%$ se ocupa en actividades económicas del sector terciario relacionadas con servicios financieros, inmobiliarios, seguros, comercio, alojamiento temporal, así como preparación de alimentos y bebidas (Instituto Nacional de Estadística y Geografía, 2011; Comité Estatal de Informacion Estadistica y Geografica de Chiapas [CEIEG], 2013).

La política estatal ha estado orientada a detonar la inversión privada y a posicionar al turismo como una actividad estratégica y prioritaria para el desarrollo económico de Chiapas (Centro de Investigación y Estudios Turísticos del Tecnológico de Monterrey, 2009). Aunado a ello, y con la finalidad de alinear su política a las prioridades de la Federación, el gobierno estatal ha favorecido la promoción de destinos con patrimonio cultural e histórico que apoyen la identidad nacional, proyecten y contribuyan a posicionar a México como destino cultural.

En este sentido, Chiapas basa su oferta turística en "su diversidad cultural y natural, en la magia de sus pueblos, sus fiestas, tradiciones, expresiones, el misticismo de su herencia ancestral maya, sus playas y sabores" (Sectur Chiapas, s.f.). Resalta el hecho de la consolidación de esta entidad como destino turístico al verse favorecida por las siguientes acciones: la declaratoria de Palenque como patrimonio de la humanidad en 1987, y de San Cristóbal de Las Casas como zona de monumentos históricos en 1986 y su posterior nombramiento como pueblo mágico en 2003; ello sumado a las diferentes declaratorias como zonas de monumentos históricos y patrimonio cultural inmaterial de la humanidad. En consecuencia, la afluencia turística ha incrementado a partir del aprovechamiento del patrimonio cultural, pero también por la conectividad de la ciudad con otros atractivos naturales y culturales.

De acuerdo con el Centro de Investigación y Estudios Turísticos del Tecnológico de Monterrey, la diversidad de destinos culturales ofertados por el estado de Chiapas fue determinante para que en 2009 y 2011 ocupara el décimo 
El Programa Pueblos Mágicos: el patrimonio cultural como generador de nuevas dinámicas en la red de política pública de Chiapa de Corzo

primer y décimo séptimo lugar nacional en captación de visitantes nacionales y el séptimo lugar en internacionales. Ese Centro también atribuye tal situación a la disponibilidad de recursos federales para el impulso turístico del estado, en específico para apoyar el turismo cultural. Según el Índice de Competitividad Turística de los Estados Mexicanos (IстEM) destacan los recursos culturales en la entidad, representados principalmente por sus pueblos indígenas, sitios arqueológicos, museos, centros culturales, monumentos históricos y sitios o expresiones denominados patrimonio de la humanidad (Centro de Investigación y Estudios Turísticos del Tecnológico de Monterrey, 2009, pp. 107-108).

Asimismo, el estado cuenta con una vasta oferta cultural, entre la que sobresalen el Museo Regional de Chiapas, el Museo de los Altos de Chiapas, el Museo Arqueológico del Soconusco y el Museo Arqueológico de Comitán; en cuanto a zonas arqueológicas, las de Bonampak, Chincultic, Izapa de Palenque, Tenam y Puente, Toniná, Yaxchilán, Chiapa de Corzo, Lagartero e Iglesia Vieja (Instituto Nacional de Antropología e Historia [INAH], 2014).

De manera complementaria, su oferta cultural se fortaleció tras las declaratorias en el 2000 de Comitán de Domínguez y de Chiapa de Corzo como zonas de monumentos históricos (Gálvez, 2009, p. 249) y su posterior nombramiento como pueblos mágicos. De igual forma influye la declaratoria de la Danza del Parachico como patrimonio cultural inmaterial de la humanidad por parte de la Unesco en 2010.

\section{El Programa Pueblos Mágicos en Chiapa de Corzo, Chiapas}

El municipio de Chiapa de Corzo se ubica en la región metropolitana del estado; colinda con los municipios de Soyaló y Usumacinta al norte, con Villa Corzo al sur, con Acala al este, con Zinacantán e Ixtapa al noreste, con Venustiano Carranza al sureste, con Villaflores al suroeste y con Tuxtla Gutiérrez y Suchiapa al oeste (Secretaría de Desarrollo Social [Sedesol], 2013).

Comprende 284 localidades (Sedesol, 2013) entre las que destacan la cabecera municipal y los barrios de San Jacinto, San Antonio Abad, Santo Tomás y San Miguel que agrupan los servicios turísticos más relevantes, entre ellos los principales embarcaderos para acceder al Cañón del Sumidero, que a su vez representa uno de los atractivos más emblemáticos, al igual que la pila colonial 


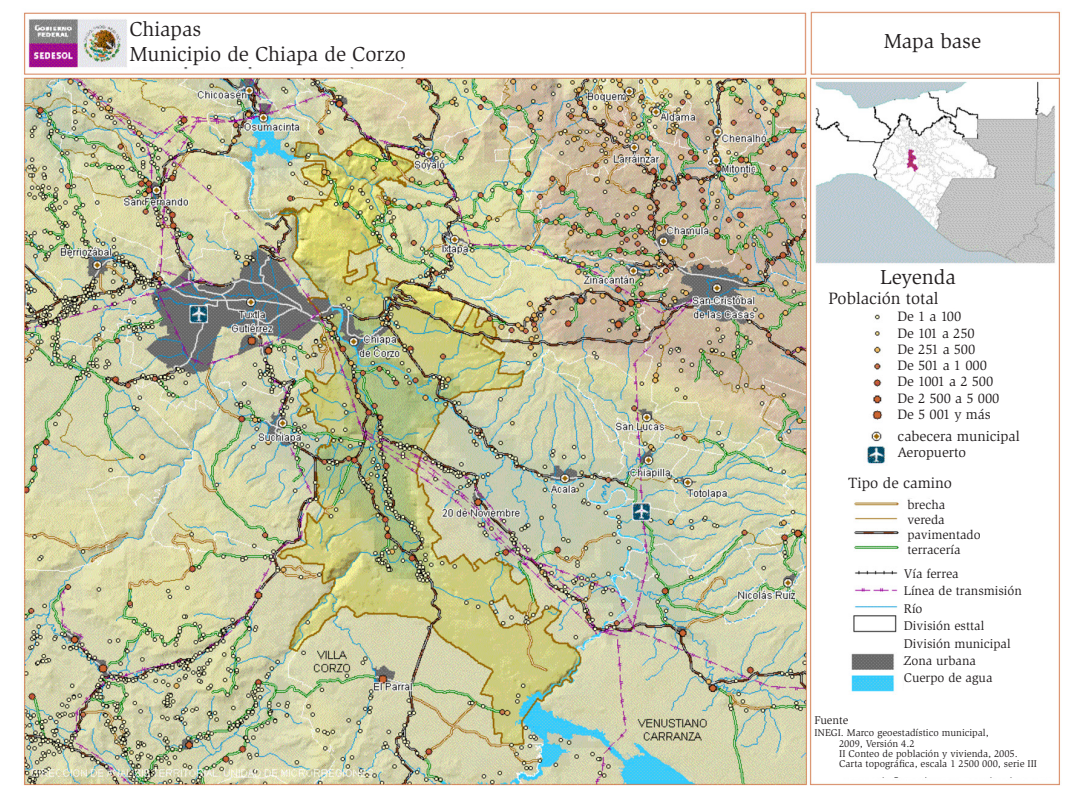

Fuente: Sedesol (2013).

Figura 1. Municipio de Chiapa de Corzo

de Chiapa de Corzo, también conocida como Fuente Mudéjar construida en 1860 (Sectur Chiapas, 2015). Otros sitios de atracción son el templo y exconvento de Santo Domingo, las ruinas del templo de San Sebastián y la zona arqueológica, acondicionada por el INAH para su visita a partir de 2009. Asimismo, la cabecera municipal y los barrios referidos ofertan restaurantes, bares, hoteles y locales de venta de artesanías.

Chiapa de Corzo se ha caracterizado por una fuerte herencia cultural representada en diversas manifestaciones susceptibles de aprovechamiento turístico; las más importantes son el camino sagrado de los floreros o la topada de la flor. Esta tradición consiste en realizar una peregrinación de siete días durante el mes de diciembre con la finalidad de recabar flores de indiluyarilú o flor de niluyarilo que sirven para montar un nacimiento en la iglesia de Santo Domingo de Guzmán. Otro atractivo es la Semana Santa, cuando se elaboran chamales (ramilletes con figuras de hojas de tempisque o tempistle, hoja morada y pétalos de flor de mayo y buganvilia). Como parte de la Fiesta Grande realizada 
El Programa Pueblos Mágicos: el patrimonio cultural como generador de nuevas dinámicas en la red de política pública de Chiapa de Corzo

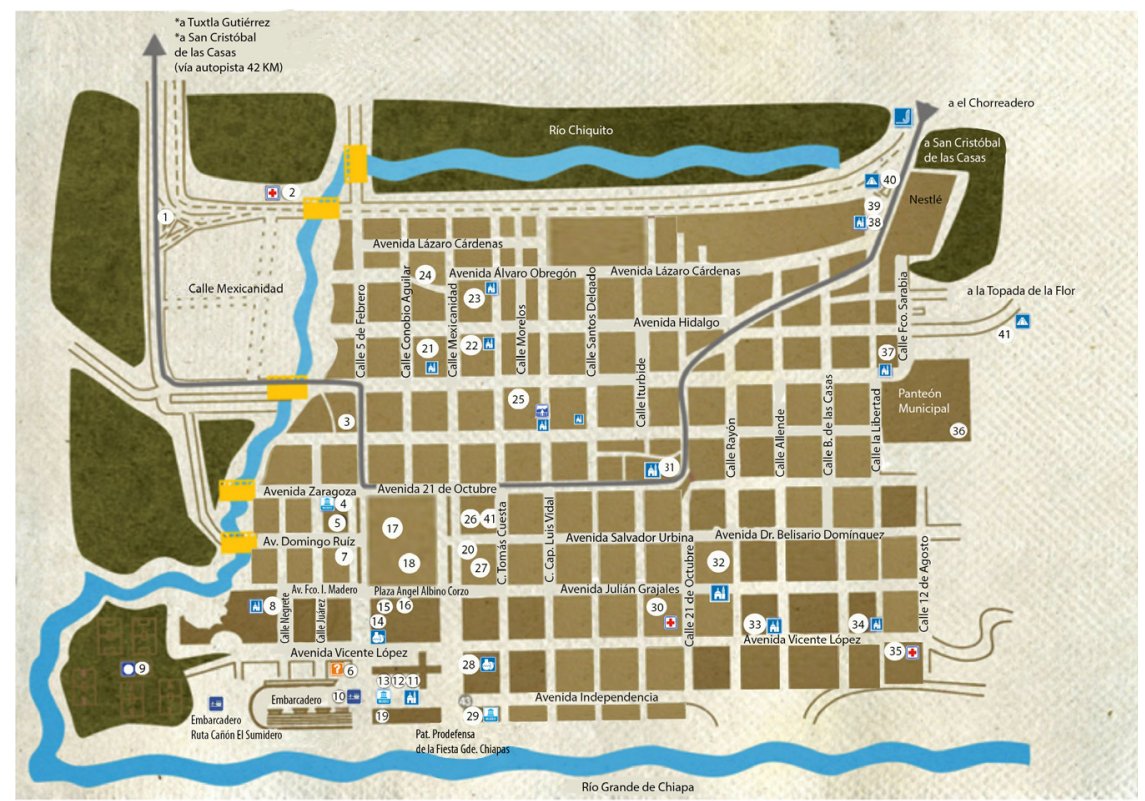

Fuente: www.turismochiapas.gob.mx

Figura 2. Centro histórico de Chiapa de Corzo

en el mes de enero destaca la Danza del Parachico, que fue declarada por la Unesco como patrimonio cultural inmaterial de la humanidad en 2010 (INAH, 2014). Resalta además la realización de artesanías como madera tallada, laca, bordado y la elaboración de marimbas.

Pese a ello, falta información oficial sobre la orientación y consolidación de Chiapa de Corzo en cuanto destino turístico, lo que hace cuestionar si su concepción como tal obedeció a alguno de los siguientes tres aspectos: la construcción de la presa de Chicoasén, acción que conlleva la declaratoria del Cañón del Sumidero como parque nacional en 1980, que tuvo la finalidad de evitar mayor afectación de la flora y fauna del río Grijalva (Comisión Nacional de Áreas Naturales Protegidas [Conanp], 1980); su cercanía a la capital del estado, o por ubicarse en el paso entre Tuxtla y San Cristóbal de Las Casas.

La transición de Chiapa de Corzo como destino turístico se ha dado de forma gradual; a partir de 2008 fue objeto de mayor atención por parte de las 
autoridades estatales y municipales, cuando iniciaron la gestión para integrarlo al producto turístico denominado Senda de Colores, junto con Comitán de Domínguez, San Cristóbal de Las Casas, Palenque y Tuxtla Gutiérrez. Senda de Colores se consolidó en 2010, con el principal objetivo de difundir y promocionar a los municipios que lo integran, mediante campañas publicitarias en radio, televisión e internet. En este propósito participaron la Sectur, la Secretaría de Economía, el Instituto de Comunicación Social y los propios municipios. Aunque este producto turístico no tuvo mayor proyección, representa el interés inicial de los gobiernos estatales y municipales por posicionar esos sitios como nuevos espacios para el turismo.

También en 2008 inició el proceso de solicitud del nombramiento de Chiapa de Corzo, dando seguimiento a la carta emitida en 2007 por la agrupación Chiapa de Corzo en el Distrito Federal A. C., donde expresa su interés por recibir el nombramiento de pueblo mágico. El proceso continuó con la redacción del expediente solicitado por la Sectur, el cual se integró con el apoyo de trabajadores del ayuntamiento, representantes de la Dirección de Turismo, Cultura, Tradición y Fomento Artesanal, y los prestadores de servicios turísticos; posteriormente estos actores integraron el Consejo Consultivo de Promoción y Desarrollo Municipal, considerado el antecedente formal del Comité Pueblo Mágico. Finalmente, en 2011 la Comisión Interinstitucional Federal ratificó la declaratoria y nombramiento de Chiapa de Corzo como pueblo mágico (Expediente Pueblos Mágicos Chiapa de Corzo).

A partir de ese hecho se han producido algunos cambios en Chiapa de Corzo vinculados principalmente con equipamiento urbano y la mejora de su infraestructura e imagen en el primer cuadro. Las primeras modificaciones fueron la iluminación de la Plaza de Armas, la presidencia municipal y la iglesia de Santo Domingo. Asimismo la reubicación de los vendedores del malecón hacia una plaza que, sin embargo, está abandonada, por lo que persisten problemas de ambulantaje y de comercio informal. También se adaptó un terreno como estacionamiento para la recepción de autobuses de turismo, pero tampoco está en funcionamiento (trabajo de campo, 2014).

De manera paralela se consideró como tarea prioritaria del gobierno estatal y municipal el reconocimiento y conservación del patrimonio, acción que dio paso a la intervención de actores correspondientes a dependencias e instituciones 
El Programa Pueblos Mágicos: el patrimonio cultural como generador de nuevas dinámicas en la red de política pública de Chiapa de Corzo

vinculadas con la salvaguarda del patrimonio, aunque también de otros actores no gubernamentales interesados en el tema. Entre ellos destaca la participación de Katyna De la Vega, secretaria de Turismo del estado de Chiapas en el periodo 2003-2005, en calidad de gestora de la declaratoria de Chiapa de Corzo como zona de monumentos históricos y de la Danza del Parachico como patrimonio cultural inmaterial de la humanidad (De la Vega, 2012: 62).

A pesar del esfuerzo por conservar el patrimonio, se han presentado algunas quejas e inconformidades sobre el manejo que hace la empresa constructora encargada de realizar la rehabilitación del exconvento de Santo Domingo y de la pila: Diseño, Construcción y Restauración S. A. de C. V. Con la finalidad de atender esta situación se observa un seguimiento por parte del Observatorio para la Salvaguarda del Patrimonio Cultural Material e Inmaterial de Chiapas, creado en 2014 (Cuarto Poder, 2014).

Asimismo, el gobierno municipal y estatal en conjunto con el Comité Pueblos Mágicos han proyectado la asignación de recursos federales para la instalación y mantenimiento del cableado subterráneo en los barrios de San Jacinto, San Antonio Abad, Santo Tomás y San Miguel como seguimiento de las restauraciones que se han realizado al exconvento, la pila y el equipamiento de la Plaza de Armas. Por su parte, los integrantes del Comité Pueblos Mágicos prepararon una serie de acciones encaminadas a cumplir los lineamientos del programa, enfatizando la necesidad de elaborar un Plan de Rescate de Espacios Culturales.

La incorporación de la localidad a ese programa dio lugar a que se vincularan actores locales gubernamentales y no gubernamentales con intereses intersectoriales comunes, aunque en ocasiones divergentes sobre el manejo del programa. De aquí destaca la intervención de actores empresariales vinculados con la actividad turística, pero también con la salvaguarda del patrimonio y la cultura (empresarios, prestadores de servicios, representantes de organismos y dependencias gubernamentales y otros actores no gubernamentales).

El análisis respecto a las relaciones e interacciones entre ellos, así como las condiciones en que estas se establecieron, además de las características y el papel de los actores dentro de una red de política pública, es el objetivo central de la investigación en que está basado este documento. 


\section{Acercamiento metodológico a la red de política pública de Pueblos Mágicos en Chiapa de Corzo}

Una red de política pública es definida como "un conjunto de relaciones relativamente estables, de naturaleza no jerárquica e independiente que vinculan a una variedad de actores que comparten intereses comunes en referencia a una política” (Börzel, 1998: 258). De acuerdo con Porras (2007), Cruz et al. (2010) y Esmark (2003), este tipo de red se integra por actores vinculados a élites económicas y políticas con características similares dependiendo del interés sectorial y el contexto en el que se ubican, así como de sus intereses comunes respecto a la elaboración de políticas públicas.

La importancia de estas redes es que funcionan como estructuras que permiten comprender el papel individual de los actores que las conforman y su postura frente a un problema determinado. En este caso se plantea que las interacciones resultantes entre los actores se caracterizan por la interdependencia de recursos y por presentar condiciones en las que las interacciones no funcionan mediante redes horizontales, es decir, no hay una distribución equitativa del poder entre los diversos actores.

Para apoyar empíricamente esta propuesta teórica, en términos metodológicos se realizó un primer acercamiento a la realidad de estudio durante 2014, que permitió identificar a los actores locales relacionados con la implementación del Programa Pueblos Mágico. En ese sentido, la metodología incluye como uno de sus aspectos más importantes el mapeo de actores, técnica que hace posible obtener información sobre los actores que participan en una estrategia o proceso; en este caso, ha proporcionado elementos respecto al proceso de nombramiento de Chiapa de Corzo como pueblo mágico.

La información obtenida permitirá, en una segunda etapa de la investigación en que está basada esta colaboración, identificar las condiciones bajo las cuales se constituye la red, además de las relaciones que establecen los actores, su grado de participación, las interacciones, alianzas y coaliciones que pueden propiciar la clausura de la red o la captura por parte de un grupo dominante, o el favorecimiento de intereses privados mediante su incorporación como parte de la política turística (Gonzalo y Gorjón, 2012, p. 87).

El listado o mapeo referido se integró con información derivada de fuentes bibliográficas, hemerográficas, normativas y documentales. Destaca la corres- 
El Programa Pueblos Mágicos: el patrimonio cultural como generador de nuevas dinámicas en la red de política pública de Chiapa de Corzo

pondiente a los siguientes documentos oficiales: Expediente Técnico Pueblos Mágicos de Chiapa de Corzo, documento de evaluación del expediente emitido por el Comité Interinstitucional de Evaluación y Selección; dictamen de certificación; Plan de Desarrollo Turístico, así como la carta de solicitud de Declaratoria de Reconocimiento de los Danzantes "Parachicos” en la Fiesta Tradicional de Enero de Chiapa de Corzo como Patrimonio Inmaterial dirigido a la Unesco.

De forma complementaria, en la primera visita de campo realizada se obtuvo información sobre aquellos actores que no estaban incluidos en los documentos consultados aun cuando intervinieron en alguna de las siguientes etapas: 2008-2011 (propuesta, integración, entrega y evaluación del expediente), 2012 (otorgamiento del nombramiento) y 2014 (ajuste en lineamientos y evaluación de cumplimiento).

Asimismo, durante esa primera visita fue contactado un informante clave o sponsor, que, según Hall (2014, p. 6), sirve de enlace para acceder a otros actores, sobre todo a los que forman parte de dependencias gubernamentales y del comité. La intermediación del sponsor ha facilitado el acceso para obtener información de estos actores.

El mapeo se integró con los siguientes personajes:

1. Los actores que participaron durante la primera etapa (2008-2011), correspondiente a la integración del expediente técnico de Pueblos Mágicos enviado a la Sectur para la revisión del cumplimiento de los requerimientos.

2. Los actores que formaron parte del Comité Pueblos Mágicos de 2012 a 2014.

3. Los actores que no formaron parte del comité, pero sí intervinieron en el funcionamiento del programa.

Para identificar a aquellos que serían entrevistados en 2015, se clasificó a los actores en los siguientes grupos:

1. Dependencias gubernamentales

a) Gobierno estatal

- Secretaría de Turismo del Estado de Chiapas

- Representantes del INAH

b) Gobierno municipal

- $\quad$ Ayuntamiento de Chiapa de Corzo 
- Delegación de Turismo

- Dirección de Turismo, Cultura, Tradición y Fomento Artesanal (2012-2015)

- $\quad$ Representantes del Colegio de Arquitectos

2. Empresariales

a) Hoteles

b) Restaurantes

c) Sociedades cooperativas de lanchas

d) Tiendas de artesanías

e) Asociación Mexicana de Hoteles y Moteles del Centro de Chiapas

f) Cámara Nacional de la Industria de Restaurantes y Alimentos Condimentados Chiapas

3. Academia

4. Sociedad civil

a) Representantes comités de barrios

b) Cronistas e historiadores

c) Artesanos

d) Actores involucrados con la salvaguarda del patrimonio cultural

Las entrevistas se realizaron en 2015 a los actores implicados en el nombramiento de Chiapa de Corzo como pueblo mágico desde 2008 hasta su evaluación en 2014. Tal corte responde a que estos conocen el proceso del nombramiento de la localidad, el Programa Pueblos Mágicos y los proyectos que se concibieron para Chiapa de Corzo. De manera particular tienen referentes sobre los procesos participativos e informativos que se constituyeron a raíz de la concepción de la localidad como pueblo mágico. La información recopilada se examinará haciendo uso del programa informático UCINET, que propicia el tratamiento de datos y su representación de forma gráfica, posibilitando así su análisis y visualización. Esta contendrá a los actores que conforman la red y la frecuencia con que interactúan; a partir de estos elementos serán analizados los vínculos entre los personajes que interactúan alrededor del Programa Pueblos Mágicos en Chiapa de Corzo. 
El Programa Pueblos Mágicos: el patrimonio cultural como generador de nuevas dinámicas en la red de política pública de Chiapa de Corzo

\section{Consideraciones finales}

El creciente cuestionamiento sobre el funcionamiento del Programa Pueblos Mágicos es, sin duda, un tema recurrente en la literatura que se ha centrado prioritariamente en sus efectos económicos. Esto evidencia la necesidad de generar investigación que posibilite identificar otras dinámicas presentes en las localidades que ostentan tal nombramiento. Una forma de contribuir con este objetivo es estudiar las redes donde participan diversos actores gubernamentales y no gubernamentales vinculados con el turismo y la salvaguarda del patrimonio.

Su importancia radica en las relaciones y acuerdos establecidos por quienes integran las redes de política pública, ya que inciden no solo en el alcance de los objetivos del programa, sino también en sus implicaciones sobre el patrimonio cultural material e inmaterial de la localidad donde se lleve a cabo la actividad turística.

Como parte de esta tarea es pertinente identificar a los integrantes de la red, así como su papel en el establecimiento de acuerdos. De estos, es de especial relevancia la participación de los actores empresariales, encaminada a la atención de sus intereses económicos o de otra índole mediante el aprovechamiento del programa y, por ende, del patrimonio cultural.

Con base en estos elementos es posible argumentar que la constitución de la red de política pública en Chiapa de Corzo a partir de su nombramiento como pueblo mágico ha generado nuevas dinámicas colaborativas entre los actores implicados, lo cual les facilita ser parte activa en la toma de decisiones; por otro lado, y como resultado de estas interacciones, se requiere identificar la contribución de estos actores en el logro de objetivos en función de los intereses colectivos. Se infiere que las relaciones gestadas entre actores gubernamentales y no gubernamentales, y su intervención como integrantes de una red, permite al gobierno establecer relaciones con personajes primordialmente empresariales, con la finalidad de conservar su papel en cuanto actor central respecto al manejo del programa como parte de una política turística.

Asimismo, el vínculo creado entre los integrantes de la red implica la conjunción de intereses respecto al manejo y funcionamiento del programa, con el propósito de obtener un beneficio económico, legitimidad o incluso formalidad. 
Finalmente, se espera que este artículo contribuya a generar una reflexión, derivada del enfoque de redes de política, sobre la serie de aspectos inherentes a la puesta en marcha de una política turística, en este caso la correspondiente al Programa Pueblos Mágicos y su aplicación a un caso local: Chiapa de Corzo, Chiapas.

\section{Fuentes consultadas}

Aceves, S. (2005). La experiencia mexicana en la gestión de su patrimonio histórico como recurso turístico. En B. Aceves (ed.), Patrimonio cultural y turismo. Cuadernos 3. Pensamiento acerca del patrimonio cultural. Antología de textos (pp. 211-221). México: Consejo Nacional para la Cultura y las Artes.

Almirón, A., Bertoncello, R. y Troncoso, C. (2006). Turismo, patrimonio y territorio. Una discusión de sus relaciones a partir de casos de Argentina. Estudios y Perspectivas en Turismo, 15(2), 101-120.

Ávila, M. (2007). Turismo cultural en México. Alcances y perspectivas. México: Trillas.

Ballart, J. (2005). Patrimonio cultural y turismo sostenible en el espacio iberoamericano: retos y oportunidades del presente. Diálogos. Revista do Departamento de História e do Programa de Pós-Graduação em História, 9(1), 11-21.

Ballart, J. y Juan-Tresserras, J. (2005). El patrimonio y el turismo. En B. Aceves (ed.), Patrimonio cultural y turismo. Cuadernos 3. Pensamiento acerca del patrimonio cultural. Antología de textos (pp. 161-187). México: Consejo Nacional para la Cultura y las Artes.

Börzel, T. (1998). Organizing Babylon-On the Different Conceptions of Policy Networks. Public Administration, 76(2), 253-273.

Casas Jurado, A. C., Soler Domingo, A. y Pastor, V. J. (2012). El turismo comunitario como instrumento de erradicación de la pobreza: Potencialidades para su desarrollo en Cuzco (Perú). Cuadernos de Turismo, 30, 91-108. Castellanos, A. (2008). Turismo, identidad y exclusión: una mirada desde Oaxaca. En A. Castellanos y A. Machuca (coords.), Turismo, identidades y 
El Programa Pueblos Mágicos: el patrimonio cultural como generador de nuevas dinámicas en la red de política pública de Chiapa de Corzo

exclusión (pp. 143-182). México: Juan Pablos/Universidad Autónoma Metropolitana.

Castillo, M., Peñaloza, L. y Tamayo, A. (2008). Las políticas turísticas culturales en el Estado de México. Gestión Turística, 9, 87-106.

Centro de Investigación y Estudios Turísticos del Tecnológico de Monterrey (2009). Índice de Competitividad Turística de los Estados Mexicanos ICTEM. Morelia: Autor.

Comisión Nacional de Áreas Naturales Protegidas (1980). Decreto por el que se declara Parque Nacional, con el nombre de Cañón del Sumidero el área descrita en el Considerando Quinto, y se expropia en favor del Gobierno Federal una superficie de 217.894,190.00 M2., ubicada en el Estado de Chiapas. http://www.conanp.gob.mx/sig/decretos/parques/Sumidero.pdf

Comité Estatal de Informacion Estadistica y Geografica de Chiapas (junio de 2013). Boletín Económico de Chiapas. Gobierno del Estado de Chiapas.

Cruz, G. et al. (2010). Redes de política pública y turismo en San Miguel Almaya. ¿Promotoras o limitantes del desarrollo local? Estudios y Perspectivas en Turismo, 19(5), 792-811.

De la Vega, K. (2012). Una experiencia de políticas culturales para favorecer la identidad cultural. Cuadernos Patrimonio Cultural y Turismo. 19, 61-67.

Duterme, B. (2008). Expansión del turismo internacional: ganadores y perdedores. En A. Castellanos y A. Machuca (coords.), Turismo, identidades y exclusión (pp. 11-29). México: Juan Pablos/Universidad Autónoma Metropolitana.

Esmark, A. (2003). Network governance between publics and elites (Working paper 2003:2). Roskilde: Centre for Democratic Network Governance-Roskilde University. Recuperado de http://rudar.ruc.dk/bitstream/1800/4142/1/Working_Paper_2003_2.pdf

Fernández, E. (2006). De tesoro ilustrado a recurso turístico: el cambiante significado del patrimonio cultural. PASOS. Revista de Turismo y Patrimonio Cultural, 4(1), 1-12.

Florescano, E. (2005). El patrimonio nacional: valores, usos, estudios y difusión. En B. Aceves (ed.), Patrimonio cultural y turismo. Cuadernos 3. Pensamiento acerca del patrimonio cultural. Antología de textos (pp. 
33-44). México: Consejo Nacional para la Cultura y las Artes.

Gálvez, L. (2009). El patrimonio cultural. Las zonas de monumentos históricos. México: Cámara de Diputados, LX Legislatura.

García, D. y Guerrero, H. (2014). El programa "Pueblos Mágicos”: análisis de los resultados de una consulta local ciudadana. El caso de Cuitzeo, Michoacán, México. Economía y Sociedad, XVIII(31), 71-94.

García, A. (2015). El relato de la marca Pueblos Mágicos: una interpretación desde las narrativas del patrimonio arquitectónico. Sexto Coloquio Internacional Ciudades del Turismo. Gestionar, viajar y otras formas de apropiación patrimonial. 10, 11 y 12 de junio 2015. Facultad de Arquitectura, UnAm.

Hall, M. (2014). Elite interviews: critical practice and tourism. Journal Current Issues in Tourism. 17(9), 832-848.

Hernández, J. (2009). Tequila: centro mágico, pueblo tradicional. ¿Patrimonialización o privatización? Andamios, 6(12), 41-67.

Hoyos, G. y Hernández, O. (2008). Localidades con recursos turísticos y el programa pueblos mágicos en medio del proceso de la nueva ruralidad. Los casos de Tepotzotlán y Valle de Bravo en el Estado de México. Quivera, 10(2), 111-130.

Instituto Nacional de Antropología e Historia (2014). Los 'parachicos’ de Chiapa de Corzo. Patrimonio cultural inmaterial de la humanidad. Diario de Campo, 2, 65-75.

Instituto Nacional de Estadística y Geografía (2011). Panorama sociodemográfico de Chiapas. México: Autor.

Juan-Tresserras, J. (2003). Patrimonio, turismo y desarrollo local: situación y perspectivas. Portal Iberoamericano de Gestión Cultural. Recuperado de: http://www.gestioncultural.org/ficheros/1_1321272045_JJuan_PatrimTurDes.pdf

Klijn, E. (1998). Policy Networks: An Overview. En W. J. M. Kickert y J. F. Koppenjan (eds.), Managing Complex Networks. Londres: Sage.

Lara, F. y López, T. (2005). El turismo como motor de desarrollo económico en ciudades patrimonio de la humanidad. PASOS. Revista de Turismo y Patrimonio Cultural, 2(2), 243-256. 
El Programa Pueblos Mágicos: el patrimonio cultural como generador de nuevas dinámicas en la red de política pública de Chiapa de Corzo

Machuca, J. A. (2008). Estrategias turísticas y segregación socioterritorial en regiones indígenas. En A. Castellanos y A. Machuca (coords.), Turismo, identidades y exclusión (pp. 51-96). México: Juan Pablos/Universidad Autónoma Metropolitana.

Marín, G. (2008). Territorio de resistencia, integración mercantil y producción del espacio turístico en Quintana Roo: trayectorias y transformaciones del mundo maya. En A. Castellanos y A. Machuca (coords.), Turismo, identidades y exclusión (pp. 97-142). México: Juan Pablos/Universidad Autónoma Metropolitana.

Méndez, E. (2012). Re-significación de lugares turísticos. Álamos y El Fuerte bajo la intervención del Programa Pueblos Mágicos en 2012. Topofilia. Revista de Arquitectura, Urbanismo y Ciencias Sociales, III(2), 1-20.

Méndez, E. (junio de 2015). Metáfora y narrativa. La magia de los pueblos, un relato para el turismo. Conferencia magistral Sexto Coloquio Internacional Ciudades del Turismo. Gestionar, viajar y otras formas de apropiación patrimonial. Facultad de Arquitectura, unAm.

Molano, L. (2007). Identidad cultural, un concepto que evoluciona. Revista Opera, 7, 69-84.

Muñiz-Montero, I. (2012). Defensa y conservación del patrimonio cultural en la ciudad de Cholula, México: El caso de Procholula A. C. Agricultura, Sociedad y Desarrollo, 9(3), 231-250.

Palafox, A., Madrigal, D. y Zizumbo, L. (2011). Apropiación, funcionalización y homogenización del espacio para el desarrollo turístico de Quintana Roo, México. Cuaderno Virtual de Turismo, 11(2), 282-293.

Porras, F. (2007). Rethinking Local Governance: Hierarchies and Networks in Mexican Cities. European Review of Latin American and Caribbean Studies, 83, 43-59.

Presidencia de la República (6 de mayo de 1972). Ley Federal sobre Monumentos y Zonas Arqueológicos, Artísticos e Históricos. Diario Oficial de la Federación.

Rodríguez, C. y Pérez, E. (2015). Turismo cultural y políticas públicas en México. El programa Pueblos Mágicos entre el desarrollo económico y la explota- 
ción del patrimonio tangible e intangible. Sexto Coloquio Internacional Ciudades del Turismo. Gestionar, viajar y otras formas de apropiación patrimonial. Facultad de Arquitectura, UnAM.

Santana, A. (1998). Patrimonio cultural y turismo: reflexiones y dudas de un anfitrión. Ciencia y Mar, 6, 37-41. Recuperado de http://www.uco. es/ gt1tomam/master/gestion/santana.pdf

Secretaría de Desarrollo Social (2013a). Unidad Microrregiones. Cédula de Información Municipal. Recuperado de http://www.microrregiones.gob. $\mathrm{mx} /$ zap/datGenerales .aspx?entra $=$ pdzp\&ent $=07 \&$ mun $=027$

Secretaría de Desarrollo Social (2013b). Catálogo de localidades. Recuperado de http://www.microrregiones.gob.mx/catloc/LocdeMun.aspx?tipo = cla ve\&campo $=$ loc\&ent $=07 \&$ mun $=027$

Secretaría de Turismo (2015). Gobierno del Estado de Chiapas. http://www. chiapas.gob.mx/conoce-chiapa-de-corzo

Talledos, E. (2012). La imposición de un espacio: de La Crucecita a Bahías de Huatulco. Revista Mexicana de Ciencias Políticas y Sociales, LVII(216), 119-142.

Organización de las Naciones Unidas para la Educación, la Ciencia y la Cultura. (1973). Acta de la Conferencia General $17^{a}$ Reunión. Volumen 1. Resoluciones, Recomendaciones. Lovaina: Autor.

Valenzuela, A., Saldaña, M. y Vélez, G. (2013). Territorios rebeldes: la puesta en valor del patrimonio cultural en Tepoztlán, México. PASOS. Revista de Turismo y Patrimonio Cultural, 11(4), 649-660.

Vega, D. y Guerrero, H. (2014). El programa “Pueblos Mágicos”: análisis de los resultados de una consulta local ciudadana. El caso de Cuitzeo, Michoacán, México. Economía y Sociedad, XVIII(31), 71-94.

Vega, K. de la (2012). Una experiencia de políticas culturales para favorecer la identidad cultural. Cuadernos Patrimonio Cultural y Turismo, 19, 61-67.

Velasco, M. (2009). Gestión turística del patrimonio cultural: enfoques para un desarrollo sostenible del turismo cultural. Cuadernos de Turismo, 23, 237-253.

Velázquez, M. A. (2013). La formulación de las políticas públicas de turismo en México. El caso del programa federal "Pueblos Mágicos” 2001-2012. Diálogos Latinoamericanos, 21, 89-110. 
El Programa Pueblos Mágicos: el patrimonio cultural como generador de nuevas dinámicas en la red de política pública de Chiapa de Corzo

Venturini, E. (2003). Patrimonio cultural, turismo y desarrollo local: El camino de las estancias jesuitas de Córdoba. Aportes y Transferencias, 7, 1, 45-64.

Zabaleta, D. (2006). Espacios multiorganizativos de políticas y conformación de redes de política en los municipios urbanos mexicanos. El caso de la política de protección y conservación del Centros Histórico de Morelia, Michoacán. México: El Colegio de México. 